\title{
Lessons from the Past: Reviewing How We Teach Science, What's Changed, and Why It Matters
}

\section{John L., Rudolph (2019) How We Teach Science: What's Changed, and Why It Matters. Harvard University Press, Cambridge. ISBN 978067491341, 320 pages, price: $\$ 36.00$ (Hardcover)}

\section{Maria Kolovou ${ }^{1}$ D}

Accepted: 29 July 2021 /Published online: 10 August 2021

(c) The Author(s), under exclusive licence to Springer Nature B.V. 2021

In his book, How we teach science, what's changed, and why it matters, John L. Rudolph unfolds the history of science education reforms in the USA for the last 130 years. Through an engaging narrative, Rudolph encourages the reader to explore some important questions and to reflect on some substantial arguments.

\section{How We Teach Science?}

As the chapters of the book unfold, Rudolph strengthens his main argument, namely that the pedagogical choices about how science was taught were always dictated by the justification about why science should be taught. In other words, the question "how to teach science" goes hand in hand with the question "why to teach science." Therefore, one of the threads that Rudolph untangles is what the purpose for teaching science has been throughout the decades.

For one thing, the purpose has not been consistent. In the mid-1800s, it was about the utilitarian value of scientific knowledge. In the end of nineteenth century, it was about the moral purpose of science education-learning science for intellectual development. In the 1950s, it was about gaining public support for research in the USA. Rudolph uses the metaphor of a pendulum that swings back and forth. What is the pattern of the different cycles of the swings? This is just another endeavor that Rudolph undertakes with this book: he studies the pattern; he names the different tendencies; the utilitarian versus the moral uplift argument; the focus on student interest versus the disciplinary knowledge.

Maria Kolovou

mxk1058@miami.edu

1 School of Education and Human Development, Teaching and Learning, University of Miami, Miami, USA 


\section{What's Changed in Science Education?}

Although Rudolph uses the metaphor of the pendulum, he also clarifies that such a metaphor is misleading, since a careful reading through the history of science education reforms will reveal that each pendulum swing represents unparalleled events that emerged in different historical contexts. In fact, one of the most important arguments of the book is that the science education purpose was always linked to the social context of its time. Rudolph supports this argument through ample and dense information about the US sociopolitical context of the four periods he studies.

Chapters 1 and 2 outline the first period of interest: the mid-nineteenth century until the late 1880s. For those who might be surprised that the book's narration starts so late in time, Rudolph reminds them that science is a relevantly recent addition to the school curriculum. This might be an important reminder, because the high status that sciences hold as school subject today was not always the case. In the early 1800 s, classical studies were considered the authoritarian subjects that students should study, and the incorporation of science to the school curriculum was not such an easy undertaking as one might think. Although there were voices that already advocated for the moral value of the intellectual training in the natural sciences, the argument that gained its momentum was by far the utilitarian argument. In a period of rapid population growth that asked for industrial and agricultural revolutions, why else would the US taxpayers justify the inclusion of science than for its (science's) practical and industrial applications? From the time that science education was confined to the technical school until the time that it was finally included in the general college curriculum, the utilitarian argument, through multiple voices, grew stronger and stronger. One of its most fervent advocates was Herbert Spencer, who contrasted the "ornamental" and "dusty" classical subjects of Greek and Latin-that prevailed at the time in colleges and universities - to the "relevant" and "useful" science-a science about "the efficient pursuit of manufacturing and industrial concerns," "individual health," "safety to raising children," "promoting citizenship," and even "aesthetic appreciation" (p. 18).

Considering that the recitation method was the expected method of learning at the time, teaching by the textbook and rote memorization of facts became the norm also for science. Following the civil war (second half of the nineteenth century), scientists, such as Henry Rowland and Charles Eliot, who visited German universities, returned to the USA with a different vision about how science should be taught, what became known as the laboratory method. The pendulum had started to swing from rote memorization to hands-on learning; from its utilitarian end to its moral purpose end-the celebration of doing pure science for its own sake; the emergence of the idea of science as culture. Focus shifted from the head to the hands, from the theory to the doing. One of the goals that the laboratory proponents (e.g., Henry Rowland) articulated was that, through experiments, students would learn that "there is such a thing in the world as truth."

Chapters 3, 4, and 5 outline the second period of interest: the 1890s until the first decade of the twentieth century. Stanley Hall was one of the first voices that marked a new and exciting endeavor: the inclusion of experimental psychology to discussions about how school subjects should be taught. By 1902, science educators were widely convinced that students were not engaged in the laboratory method, nor interested in "experimental science." Hall criticized the quantitative nature of the laboratory method and put at the center of the educational debates the adolescents' ways of thinking and knowing. The pendulum started to swing again toward its utilitarian end, but from another perspective this time: 
the need for science to be relevant to students' lives. John Dewey's work established what became known as progressive science education. The focus shifted from knowing facts to knowing the process of doing science, "the scientific method." Although the laboratory method did engage students in doing science, it had focused too much on accuracy of measurements; progressive educators expanded the idea of what doing science meant and brought up the goal of problem solving as an important skill to be learned.

Chapters 6, 7, and 8 outline the third period of interest: the 1950s until the latetwentieth century. After World War II, especially after the Soviet launch of Sputnik, scientists raised concerns that the five-step scientific method devalued the scientific enterprise. The method broke down the scientific processes to steps that included (a) observing a phenomenon, (b) formulating hypothesis to explain the phenomenon, (c) designing of experiment(s) to test the hypothesis, (d) conducting the experiment(s), and (e) analyzing results and drawing conclusions. What was rote memorization of facts during the first period of science education now became a rote memorization of steps, as if science were a recipe that would succeed if its steps were followed.

Scientists were worried that the five-step method gave the impression that science is simple, that anyone can do it, and, most importantly, that it does not need much time and/or effort. After all, the public had just witnessed the invention of the radar and the atomic bomb during the war, dramatic inventions that were conceived exactly when needed. To restore the oversimplified image of science in the eyes of the public, the National Science Foundation (NSF; launched in 1945) was established as a foundation that funded basic science. In the years that followed, James Conant pioneered a method for teaching science that used history-of-science cases to illuminate the paths that real scientists took. The method was an alternative to the oversimplified five-step scientific method, and, although it did not make a significant impact, it marked the return of practicing scientists in high school involvement, a role that for the last three decades was given to progressive educators. During the 1950s, scientists turned their attention to schools and worked to create new curricula, methods, and textbooks that would present the "true nature of scientific work" - this was the beginning of the "science as inquiry" approach.

Chapters 9 and 10 outline the fourth and final period of interest: the late-twentieth century until today. The unprecedented attention given to science education during the 1950s and 1960s wore down during the 1970s, when public started to lose its trust in science. As a response to what seemed like a degradation of science, the American Association for the Advancement of Science (AAAS) enacted a project led by Jim Rutherford, the Project 2061. The purpose was to rebuild science education so that to overcome the economic threat from Japan. Project 2061 was a long-term project that envisioned to include both knowledge of scientific conclusions and knowledge of the processes of generating scientific conclusions; it aspired to attend both to the nature of science and to the scientific literacy needed for an economic development.

The focus on the process of science led to the Next Generation Science Standards (NGSS), which eventually pushed students to study for standardized tests. The pressure for high achievement reversed the initially intended outcome: rather than focusing on the process of science, the interest in science classrooms shifted to the content knowledge, because the latter was easier to assess. The study of science, especially in high school, became more a matter of gaining admission to universities than a matter of deepening scientific understanding. 


\section{Why Knowing the Past of Science Education Matters}

Whether it was called the laboratory method, the scientific method, scientific inquiry, or scientific practices, throughout the history of science education reforms, educators and reformers always struggled to provide students with the methods of doing science. Why does tracing this endeavor matter?

The argument for why it matters is already outlined in the introduction of the book, but the diligent readers will be able to justify the argument themselves through attending to the details of the narration, and by the time they reach the conclusion, they will probably agree with Rudolph's point: It was never the problem of how science works, but rather of why science was taught.

Rudolph notices that educators and reformers over the years struggled to align science pedagogy with the process of science. After exposing what happened every time promising methods/reforms were applied to the classroom, Rudolph challenges this view and asks to break free from a perennial cycle of mismatches. He invites the reader to consider that teachers who teach science at schools are not scientists themselves and that (what he calls as) the nature of schooling tends to turn science to rote memorization. Dewey did not intend for the scientific method to become a five-step process to be memorized. Rutherford did not foresee that the scientific literacy he envisioned would be jeopardized. The book forces the reader to consider the what's, the why's, and the how's of the past, so that to reflect on the "now what?"

History shows that there are, indeed, multiple ways to present science and the process of science. Rudolf's suggestion is to embrace science on its whole: Students should do science, but they should also learn about theories; they should understand that there is no one way of doing science but be exposed to a range of methods. He highlights that not all theories come from experimentation (e.g., the theory of evolution) and not all scientific predictions come from direct observations (e.g., effects of climate change). Therefore, learning science only through one method would lead to misconceptions about how science works. "We should teach, in other words, that scientists know what they are talking about when it comes to things such as climate change, groundwater contamination, vaccinations, and so on" (p. 228).

Rudolph reminds the reader that how science is taught has important social consequences. After all, what happens in the science classrooms will determine how future citizens will relate to science. He draws on his own experience as a high school student when he learned the five-step scientific method and his surprise when he later realized that there is much more to the process of doing science (Noonoo, 2019, EdSurge Podcast with John Rudolph). Rudolph fears that how science has been taught relates to how citizens currently react to scientists' warnings about climate change or vaccination, concerns particularly relevant to the recent COVID-19 pandemic. In his article The lost moral purpose of science education, Rudolph (2020) showcases another way to learn from the past. He reflects on the moral purpose of science education that emerged in the late nineteenth century and wonders whether it is time that science classrooms re-introduce the intellectual and moral uplift purpose. To formulate and strengthen his argument, he draws on the context of the period that the moral uplift purpose emerged and compares it to today's socio-political context. 


\section{Concluding Thoughts About the Use of "We" in the Book's Title}

I admit that the use of "we" in the title achieves an intimate effect. After all, it is evident from the very first pages of the book that the "we" refers to US science education, rather than a universal science education. A clarifying sub-title might dissolve relevant confusion by prospective readers. But my major concern about the effect of "we" is that it highlights the absence of a discussion about "whose science" "we" teach. The book manages so successfully to link the US science education with its socio-political context, that I would welcome a reference to the different ways of doing science in different cultures. Following Rudolph's rationale, the different ways of doing science inform the different ways of teaching science. After all, the "rationalized' science that is taught in US schools is the science that comes from the West. Such a discussion might open some new opportunities/ dimensions for science learning, especially considering Rudolph's suggestion that students should embrace science "on its whole."

Publisher's note Springer Nature remains neutral with regard to jurisdictional claims in published maps and institutional affiliations. 